\title{
How to Get the Optimal Defibrillation Lead Parameters Using Myocardial Perfusion Scintigraphy in Patients With Coronary Artery Disease
}

\section{Tariel Abdilazimovich Atabekov ( $\sim$ kgma1011@mail.ru )}

Tomsk National Research Medical Center Cardiology Research Institute: Tomskij nacional'nyj issledovatel'skij medicinskij centr Naucno-issledovatel'skij institut kardiologii https://orcid.org/00000003-2645-4142

\section{Roman Efimovich Batalov}

Tomsk National Research Medical Center Cardiology Research Institute: Tomskij nacional'nyj issledovatel'skij medicinskij centr Naucno-issledovatel'skij institut kardiologii

\section{Svetlana Ivanovna Sazonova}

Tomsk National Research Medical Center Cardiology Research Institute: Tomskij nacional'nyj issledovatel'skij medicinskij centr Naucno-issledovatel'skij institut kardiologii

\section{Sergey Nikolaevich Krivolapov}

Tomsk National Research Medical Center Cardiology Research Institute: Tomskij nacional'nyj issledovatel'skij medicinskij centr Naucno-issledovatel'skij institut kardiologii

\section{Mikhail Sergeevich Khlynin}

Tomsk National Research Medical Center Cardiology Research Institute: Tomskij nacional'nyj issledovatel'skij medicinskij centr Naucno-issledovatel'skij institut kardiologii

\section{Anna Mishkina}

Tomsk National Research Medical Center Cardiology Research Institute: Tomskij nacional'nyj issledovatel'skij medicinskij centr Naucno-issledovatel'skij institut kardiologii

\section{Konstantin Valerievich Zavadovsky}

Tomsk National Research Medical Center Cardiology Research Institute: Tomskij nacional'nyj issledovatel'skij medicinskij centr Naucno-issledovatel'skij institut kardiologii

\section{Antonio Curnis}

Università degli Studi di Brescia: Universita degli Studi di Brescia

\section{Sergey Valentinovich Popov}

Tomsk National Research Medical Center Cardiology Research Institute: Tomskij nacional'nyj issledovatel'skij medicinskij centr Naucno-issledovatel'skij institut kardiologii

\section{Research Article}


Keywords: Implantable cardioverter-defibrillator, myocardial perfusion scintigraphy, pacing threshold, ventricle signal amplitude

Posted Date: May 6th, 2021

DOl: https://doi.org/10.21203/rs.3.rs-483208/v1

License: (c) (i) This work is licensed under a Creative Commons Attribution 4.0 International License. Read Full License 


\section{Abstract}

Introduction. The conventional criteria for a defibrillation lead (DL) implantation don't take into account presence of scar or deep ischemia in the myocardium. This may impair a proper functioning of the DL. We sought to optimize the DL implantation placement using rest myocardial perfusion scintigraphy (MPS), which allow detecting areas of myocardial hypoperfusion (MH).

Purpose. To study the influence of MH and scarring, detected by MPS, on the DL parameters in patients with coronary artery disease (CAD).

Methods. 69 patients (male - 65, age 64.8 \pm 7.7 years) with CAD and indications for ICD implantation were enrolled. Two days before ICD implantation all patients underwent MPS at rest. Then patients were divided in 2 groups. In the $1^{\text {st }}$ group DL was implanted considering MPS results: to the septal position, if the most significant $\mathrm{MH}$ were detected in the apical segments, and to the apical position, if $\mathrm{MH}$ were in the septal segments. In the $2^{\text {nd }}$ group DL was implanted using the conventional approach without considering MPS results. Clinical 12 months follow-up was performed with ICD interrogation.

Results. Patients of both groups were comparable by clinical and scintigraphic parameters. In the same time, in the $1^{\text {st }}$ group pacing threshold was lower $(p<0.0001)$ and ventricle signal amplitude was higher $(p<0.0001)$ comparing with the $2^{\text {nd }}$ group at all control points.

Conclusion. The presence of MH detected by MPS in the area of the DL placement worsens its parameters. The results of MPS in patients with CAD can be useful for optimization of DL placement.

\section{Introduction}

The implantable cardioverter-defibrillator (ICD) is the most effective tool to reduce the risk of sudden cardiac death (SCD) [1-4]. It reduces mortality by anti-tachycardia pacing (ATP) and ICD shock of ventricular tachycardia (VT) or fibrillation (VF) [1-4]. One of the requirements for appropriate device response is an adequate detection of the intracardiac signal. In accordance with modern guidelines [5], for the reliable detection of VT/VF, the ventricular signal amplitude (VSA) should be more than $7.0 \mathrm{mV}$ [5] Currently, ICD implantation is performed based on conventional intraoperative criteria: the defibrillation lead (DL) pacing threshold (PT) less than 1.0 V and VSA more than $5.0 \mathrm{mV}$ [6]. Beyond technical aspects, several factors may influence these measurements, including condition of the myocardial tissue surrounding the tip of the implanted lead [7-9]. In patients with prior myocardial infarction (MI) this may be due to scar or hibernated tissue with electrical heterogeneity in myocardium of the most frequently implanted positions, particularly an interventricular septum or apex. Implantation of the DL into the area with myocardial scar may impair a proper functioning of $D L$, because the scar or hibernated myocardium has electrical heterogeneity and low signal amplitude $[8,9]$. This can lead to insufficient sensitivity of the intracardiac signal detection, pacing DL fails and as a result - an inappropriate ICD-therapy. According to Powell B. et al. $27 \%$ of inappropriate ICD-therapy are due to the detection of noise, artifacts, excessive or 
insufficient sensitivity of the intracardiac signal [10]. It's important to find out an approach that can improve DL placement. Today, the most common methods for the myocardium scar assessing are echocardiography and magnetic resonance imaging [11]. In the same time, myocardial perfusion scintigraphy (MPS) is simpler, has higher reproducibility and allows detecting area of impaired myocardial flow and scarring [12]. We assumed that presence of stable hypoperfusion (scarring) detected by MPS in the area of the DL placement worsens its parameters. Also it was hypothesized that results of MPS in patients with CAD can be useful for optimization of DL placement.

\section{Methods}

\section{Patients}

A clinical, open, randomized, prospective study included patients with CAD and indications for ICD $(n=69$, average age $64.8 \pm 7.7$ years, male -65 ). Randomization was carried out using a random number table generated in a statistical program. The inclusion criteria were prior MI (more than 3 months prior), functional class of heart failure from I to III according to the classification of New York Heart Association and ICD implantation indications (primary and secondary). The exclusion criteria were: patients with contraindications for the ICD implantation, severe comorbidity, severe cognitive impairment, with indications for the revascularization, candidates for the cardioresynchronization therapy and heart transplantation.

All patients underwent full physical examination and MPS with ${ }^{99 \mathrm{~m}} \mathrm{Tc}$-methoxy-isobutyl-isonitrile $\left({ }^{99 \mathrm{~m}} \mathrm{Tc}\right.$ $\mathrm{MIBI})$ at rest 48 hours before ICD implantation $[6,12]$. Than patients were randomized into two groups. In the 1 st group $(n=40)$ DL was implanted using conventional approach (PT 1.0 V or less and VSA $5.0 \mathrm{mV}$ or more), but considering MPS results.

In the 2nd group ( $n=29)$ DL was implanted using only the conventional approach. The flow chart of the study is shown in Fig. 1.

\section{Consent}

The study was carried out in accordance with the principles of the Helsinki Declaration and with the standards of Good Clinical Practice. The study protocol was approved by the Local Ethics Committee. All participants received written informed consent prior to the study inclusion. Ethical approval by the hospital review committee and patient consent according to the institutional guidelines were obtained.

\section{Myocardial perfusion scintigraphy}

Myocardial perfusion SPECT with 740 MBq of the ${ }^{99 m}$ Tc-MIBI ("Technetril, ${ }^{99 m}$ Tc", OJSC "Diamed", Russia) was performed at rest in accordance with current guidelines of European Society of Nuclear Medicine [12]. Images were acquired on a double-head gamma camera (Forte, Philips Medical System, the Netherlands) with high-resolution collimators into a $64 \times 64$ pixel matrix. The myocardium perfusion assessment was performed using the QPS program (Cedars Sinai Medical Center, USA). Images were 
evaluated in short axis, vertical and horizontal long axes and in 17 segment polar map. The analysis of regional myocardial perfusion defects in each segment was performed using 5-point scale (from 0 to 4 ) with the calculation of the summed rest score \% (SRS \%). When processing scintigrams, myocardial perfusion defects in the apical and septal segments (on a 5-point scale (0 to 4)), which are adjacent for left and right ventricles, were separately evaluated, and these results were included into the subsequent analysis. The summed septal score (SspS) was considered as a sum of scores in basal anteroseptal, basal inferoseptal, mid-anteroseptal, mid-inferoseptal segments (Fig. 2). The summed apical score (SapS) was considered as a sum of scores in the apex, apical lateral, apical inferior and apical anterior segments (Fig. 2). The score in the apical septal segment was added for both SspS and SapS.

\section{ICD implantation and follow-up}

In the 1st group ( $n=40)$ DL was implanted to the septal position, in cases of SapS was >2) (Fig. $3 A)$, and to the apical position, if SspS was > 2 (Fig. 3B). If the SapS and SspS were the same, the DL was implanted using on conventional criteria (PT 1.0 V or less and VSA $5.0 \mathrm{mV}$ or more). If the scores at both the SapS and SspS were more than 2, then the DL was implanted to the segment with the lowest score. Also, before the DL placement, we checked its parameters, which should be met to the criteria of conventional approach (PT 1.0 V or less and VSA $5.0 \mathrm{mV}$ or more).

In the 2nd group ( $\mathrm{n}=29)$ DL was implanted using only the conventional approach (PT $1.0 \mathrm{~V}$ or less and VSA $5.0 \mathrm{mV}$ or more). ICD implantation was carried out under the fluoroscopic control with X-ray an angiographic installation of the "C-arc" type Siemens Arcadis Avantic, Germany and Siemens Cios Alpha, Germany. ICD implantation was performed under a pulsed fluoroscopy mode of 4 frames per second with a radiation dose value of "Low", based on low requirements for imaging quality, with automatic selection of X-ray tube voltage and current. PT and VSA during ICD implantation were assessed with a Medtronic CareLink $^{\text {TM }} 2090$ Programmer with integrated pacing system analyzer (USA).

All patients were followed-up prospectively in our hospital for 12 month. The information about arrhythmic events was determined from ICD interrogation reports. The parameters of ICD-lead system (PT, VSA, pace and shock impedance) and arrhythmic events (atrial fibrillation, VT, VF, appropriate and inappropriate ICD-therapy) were evaluated at control points (1st day after ICD implantation, $1 \mathrm{st}$, 6 th and 12th month after ICD implantation).

\section{Statistics}

Statistical analysis was performed using the software package Statistica 10.0, StatSoft, USA. To assess the normality of the distribution of the trait the Kolmagorov-Smirnov criterion was used. For variables with the normal distribution the mean value (M) and standard deviation (SD) were calculated, for others -

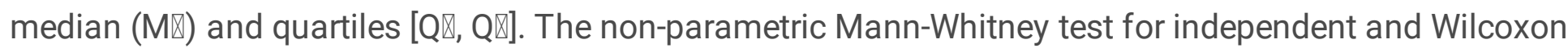
matched pairs test for dependent samples was used. We consider significant $p$ values $<0.05$. 


\section{Results}

\section{Study population}

The characteristics of patients are presented in the Table 1. According to the age, primary disease, the presence of VF, VT, atrial fibrillation (AF), a history of MI, electrocardiography, echocardiography, MPS results, comorbidity and therapy of primary disease, there were no significant differences between groups (Table 1). 
Table 1

Baseline characteristics of enrolled patients

\begin{tabular}{|c|c|c|c|}
\hline & $\begin{array}{l}\text { 1st group } \\
(n=40)\end{array}$ & $\begin{array}{l}\text { 2nd group } \\
(n=29)\end{array}$ & p \\
\hline Sex, male/female (n, \%) & $38 / 2(95.0 / 5.0 \%)$ & $27 / 2(93.1 / 6.9 \%)$ & 0.898 \\
\hline Age $(\mathrm{M} \pm \mathrm{SD}$, year $)$ & $64.2 \pm 7.4$ & $66.8 \pm 7.9$ & 0.352 \\
\hline $\begin{array}{l}\text { Prior myocardial infarction older } 3 \text { month (n, } \\
\%)\end{array}$ & $40(100.0 \%)$ & $29(100.0 \%)$ & 0.995 \\
\hline \multicolumn{4}{|l|}{ Myocardial infarction localization: } \\
\hline apical $(n, \%)$ & $25(62.5 \%)$ & $13(44.9 \%)$ & 0.214 \\
\hline septal $(n, \%)$ & $7(17.5 \%)$ & $16(55.2 \%)$ & 0.008 \\
\hline anterior (n, \%) & $5(12.5 \%)$ & $21(72.4 \%)$ & 0.001 \\
\hline posterolateral (n, \%) & $10(25.0 \%)$ & $4(13.8 \%)$ & 0.432 \\
\hline Hypertension I-III deg. (n, \%) & $18(45.0 \%)$ & $15(51.7 \%)$ & 0.639 \\
\hline \multicolumn{4}{|l|}{ NYHA functional class: } \\
\hline$I(n, \%)$ & $0(0.0 \%)$ & $3(10.3 \%)$ & 0.469 \\
\hline II $(\mathrm{n}, \%)$ & $24(60.0 \%)$ & $16(55.2 \%)$ & 0.738 \\
\hline III $(n, \%)$ & $16(40.0 \%)$ & $10(34.5 \%)$ & 0.701 \\
\hline QRS (Me [Q1-Q3], ms) & $\begin{array}{l}\text { 110.0 [100.0; } \\
120.0]\end{array}$ & $100[80 ; 120]$ & 0.068 \\
\hline QTc (Me [Q1-Q3], ms) & $\begin{array}{l}420.0[410.0 \\
453.5]\end{array}$ & $\begin{array}{l}420.0[397.0 \\
444.0]\end{array}$ & 0.567 \\
\hline LVEF (Me [Q1-Q3], \%) & $35.5[31.0 ; 44.0]$ & $42.0[35.0 ; 55.0]$ & 0.052 \\
\hline Summed rest score (Me [Q1-Q3], \%) & $20.0[13.0 ; 30.0]$ & $24.0[8.0 ; 31.0]$ & 0.927 \\
\hline Ventricle fibrillation $(\mathrm{n}, \%)$ & $0(0.0 \%)$ & $1(3.4 \%)$ & 0.812 \\
\hline Nonsustained ventricular tachycardia $(\mathrm{n}, \%)$ & $38(95.0 \%)$ & $28(96.5 \%)$ & 0.917 \\
\hline Sustained ventricular tachycardia $(n, \%)$ & $18(45.0 \%)$ & $21(72.4 \%)$ & 0.054 \\
\hline Atrial fibrillation (n, \%) & $19(47.5 \%)$ & $8(27.6 \%)$ & 0.162 \\
\hline Dyslipidemia (n, \%) & $23(57.5 \%)$ & $15(51.7 \%)$ & 0.563 \\
\hline Diabetes mellitus ( $n, \%)$ & $4(10.0 \%)$ & $3(10.3 \%)$ & 0.985 \\
\hline
\end{tabular}




\begin{tabular}{|c|c|c|c|}
\hline & $\begin{array}{l}\text { 1st group } \\
(n=40)\end{array}$ & $\begin{array}{l}\text { 2nd group } \\
(n=29)\end{array}$ & $\mathbf{p}$ \\
\hline Obesity (n, \%) & $14(35.0 \%)$ & $11(37.9 \%)$ & 0.841 \\
\hline \multicolumn{4}{|l|}{ Therapy: } \\
\hline beta-blockers (n, \%) & $40(100.0 \%)$ & $29(100.0 \%)$ & 0.995 \\
\hline amiodarone $(\mathrm{n}, \%)$ & $16(40.0 \%)$ & $15(51.7 \%)$ & 0.411 \\
\hline statins $(n, \%)$ & 40 (100.0\%) & $29(100.0 \%)$ & 0.995 \\
\hline $\begin{array}{l}\text { Angiotensin-converting enzyme inhibitors ( } \mathrm{n} \text {, } \\
\% \text { ) }\end{array}$ & $38(95.0 \%)$ & $26(89.6 \%)$ & 0.710 \\
\hline Antiplatelet agents $(\mathrm{n}, \%)$ & $40(100.0 \%)$ & $29(100.0 \%)$ & 0.995 \\
\hline Diuretic (n, \%) & $28(70.0 \%)$ & $18(62.0 \%)$ & 0.580 \\
\hline
\end{tabular}

\section{Clinical and ICD implantation data}

According to the results of MPS with ${ }^{99 \mathrm{~m}} \mathrm{Tc}-\mathrm{MIBI}$, all 69 (100.0\%) patients showed perfusion defects indicating a myocardial scar, medium SRS was $20.0 \%$ [13.0; 30.0]. An example of obtained scintigrams is presented in Fig. 4.

Results of myocardial perfusion scintigraphy with ${ }^{99 \mathrm{~m}} \mathrm{Tc}-\mathrm{MIBI}$ are presented in Table 2 . In 32 (80.0\%) of patients from the $1 \mathrm{st}$ group, perfusion defects were more significant in the apical segment then in septal segments and DL was implanted to the septum of the right ventricle. The other $8(20.0 \%)$ patients have predominantly perfusion defects in the septal segment and DL was implanted to the zone of the smallest perfusion disorders (myocardial scar), that is apex of the right ventricle. In 10 (34.5\%) patients from the 2nd group, the predominantly perfusion defects indicating a myocardial scar in the apical segment was larger than in the septal segment. The other 19 (65.5\%) patients have predominantly perfusion defects in the septal segment. But in this group DL was implanted only according to the conventional approach, in $16(55.2 \%)$ patients DL was implanted to the septal position $(p=0.081)$, and in $13(44.8 \%)$ - apical $(p=$ $0.081)$. 
Table 2

Results of myocardial perfusion scintigraphy with ${ }^{99 \mathrm{~m}} \mathrm{Tc}-\mathrm{MIBI}$

\begin{tabular}{|c|c|c|c|}
\hline & $\begin{array}{l}\text { 1st group } \\
(n=40)\end{array}$ & $\begin{array}{l}\text { 2nd group } \\
(n=29)\end{array}$ & $p$ \\
\hline Summed rest score, \% & $20.0[13.0 ; 30.0]$ & $24.0[8.0 ; 31.0]$ & 0.927 \\
\hline Summed apical score & $4.0[1.0 ; 7.0]$ & $3.0[0.0 ; 6.0]$ & 0.212 \\
\hline Summed septal score & $2.5[1.0 ; 3.0]$ & $5.0[1.0 ; 7.0]$ & 0.053 \\
\hline \multicolumn{4}{|c|}{$\begin{array}{l}\text { In the } 1 \text { st group }(n=40) \text { single-chamber ICD was implanted in } 4(10.0 \%) \text { patients, in the } 2 \text { nd group }(n \\
=29)-3(10.3 \%) \text { patients }(p=0.193) \text {, dual-chamber }-36(90.0 \%) \text { vs. } 26(89.7 \%)(p=0.274) \text {. In the } \\
1 \text { st group for } 20(50.0 \%) \text { patients ICD was implanted for primary SCD prevention, in the } 2 \text { nd group }- \\
8(27.6 \%)(p=0.287) \text {, secondary prevention }-20(50.0 \%) \text { vs. } 21(72.4 \%)(p=0.287) \text {. }\end{array}$} \\
\hline
\end{tabular}

Examples of patients with DL in septal and apical positions are presented in Fig. 5.

ICD implantation was uneventful and there were no complications and death. There was no ICD-related surgical revision during 12 month after implantation. There were no leads dysfunction (except PT increase more 1.0 V and VSA decrease less $5.0 \mathrm{mV}$ ) and dislocation.

ICD interrogation data

The follow-up for 12 month was complete in 69 (100.0\%) patients. Significant differences between patients from both groups were found for PT and VSA at all control follow-up points (Table 3). 
Table 3

Defibrillation lead indicators at control points $\mathrm{M} \otimes[\mathrm{Q} \otimes ; \mathrm{Q} \otimes]$

\begin{tabular}{|c|c|c|c|}
\hline Indicator & 1 st group, $n=40$ & 2nd group, $n=29$ & p \\
\hline \multicolumn{4}{|c|}{ 1st day after ICD implantation } \\
\hline PT, V & $0.5[0.4 ; 0.5]$ & $0.7[0.7 ; 1.1]$ & $<0.001$ \\
\hline VSA, mV & $12.5[11.7 ; 12.5]$ & $8.5[7.0 ; 10.5]$ & $<0.001$ \\
\hline Pl, Ohm & $526.0[491.0 ; 572.0]$ & $496.0[445.0 ; 501.0]$ & $<0.001$ \\
\hline SI, Ohm & $54.0[51.0 ; 65.0]$ & $58.0[54.0 ; 69.0]$ & 0.171 \\
\hline \multicolumn{4}{|c|}{ 1st month after ICD implantation } \\
\hline PT, V & $0.5[0.3 ; 0.65]$ & $1.2[0.9 ; 1.3]$ & $<0.001$ \\
\hline VSA, mV & $13.5[12.0 ; 14.5]$ & $6.0[5.0 ; 6.5]$ & $<0.001$ \\
\hline Pl, Ohm & $523.0[484.5 ; 559.5]$ & $605.0[585.0 ; 634.0]$ & $<0.001$ \\
\hline SI, Ohm & $54.0[50.5 ; 62.5]$ & $57.0[53.0 ; 60.0]$ & 0.312 \\
\hline \multicolumn{4}{|c|}{ 6th month after ICD implantation } \\
\hline PT, V & $0.5[0.3 ; 0.7]$ & $1.1[0.8 ; 1.2]$ & $<0.001$ \\
\hline VSA, mV & $13.7[12.0 ; 14.5]$ & $6.5[5.5 ; 9.6]$ & $<0.001$ \\
\hline Pl, Ohm & $496.0[442.0 ; 553.0]$ & $565.0[475.0 ; 614.0]$ & 0.012 \\
\hline Sl, Ohm & $55.0[49.5 ; 64.0]$ & $57.0[52.0 ; 60.0]$ & 0.626 \\
\hline \multicolumn{4}{|c|}{ 12th month after ICD implantation } \\
\hline $\mathrm{PT}, \mathrm{V}$ & $0.5[0.5 ; 0.65]$ & $1.1[0.9 ; 1.3]$ & $<0.001$ \\
\hline VSA, mV & $14.25[12.0 ; 15.2]$ & $6.8[5.5 ; 10.0]$ & $<0.001$ \\
\hline Pl, Ohm & 486.0 [417.0; 519.5] & $475.0[420.0 ; 574.0]$ & 0.454 \\
\hline SI, Ohm & $62.0[46.0 ; 72.0]$ & $55.0[51.0 ; 62.0]$ & 0.191 \\
\hline
\end{tabular}

PT in the 1 st group was lower than in the 2 nd group at all control points $(p<0.001)$. The PT dynamics in groups at all follow-up points is shown in the Fig. 6.

VSA in the 1st group was higher than in the 2 nd group at all follow-up points $(p<0.001)$. The VSA dynamics in groups at all follow-up points is shown in the Fig. 7. 
It should be noted that in the 1 st group in $2(5.0 \%)$ patients was registered VSA less than $7.0 \mathrm{mV}$ and in the 2 nd group $-23(79.3 \%)(p<0.001)$.

Lead impedance in the 2nd group was significantly higher than in the 1 st group on the 1 st $(p<0.001)$ and 6th $(p=0.012)$ month control follow-up points (Table 3$)$. Shock impedance did not significantly differ (Table 3). A critical increase or decrease of the pacing and shock impedance in both groups was not detected (normal pacing impedance 200-2000 Ohms, normal shock impedance 20-200 Ohms).

During 12th month follow-up an appropriate ICD-therapy was registered in $6(8.7 \%)$ patients from both groups, 2 (2.9\%) patients of them received ICD-shock, 4 (5.8\%) - ATP-therapy. In the 1 st group 4 of 40 patients $(10.0 \%)$ received an appropriate ICD-therapy, in the 2 nd group -2 of 29 patients $(6.9 \%)(p=$ $0.423)$, ICD-shock - $2(5.0 \%)$ vs. $0(0 \%)(p=0.728)$, ATP-therapy $-2(5.0 \%)$ vs. $2(6.9 \%)(p=0.845)$. In 1 st group non-sustained VT was registered in 24 of 40 patients $(60.0 \%)$ with spontaneous termination, in 2nd group - 18 of 29 patients $(62.1 \%)(p=0.888)$.

In the 1st group an inappropriate ICD-therapy (ICD-shock/ATP-therapy) was not registered. An inappropriate ICD-therapy (ICD-shock/ATP-therapy) was registered in $3(4.4 \%)$ patients from the 2nd group ( $p=0.584)$. These episodes were related with ventricular signal hyposensing, because all 3 patients had low VSA (less than $5.0 \mathrm{mV}$ ) and DL sensitivity was automatically lower. This led to T-wave oversensing on sinus tachycardia. ICD interpreted this event as VT and performed ICD-therapy.

In the 2nd group, comparison of the DL implantation site with the MPS results showed that in 11 (37.9\%) patients DL was implanted in the segment with the maximum perfusion defects. Thus, DL implantation according to the conventional approach, when the myocardial scar is not assessed before the operation, could lead to an PT increase and VSA decrease. Among these 11 patients, 3 of them have inappropriate ICD-therapy. All three patients had dual-chamber ICDs with adequate settings for VT/VF detection. It is noteworthy that the amplitude of the VSA in these patients was less than $5.0 \mathrm{mV}$ and it's could be reason of inappropriate ICD-therapy.

In this way, DL implantation in the 1st group after the radionuclide assessment of myocardial perfusion (myocardial scar) in the apical and septal segments allowed to achieve optimal PT $(p<0.001)$ and VSA $(p=0.001)$ indicators.

\section{Discussion}

The main result of our study is that DL implantation into the zone of the smallest perfusion defect (myocardial scar) allowed achieving optimal lead indicators, thereby preventing impaired detection of lifethreatening ventricular tachyarrhythmias and reducing the number of an inappropriate ICD-therapy in the early and long-term period in patients with CAD.

The search of the new approach in ICD implantation, which will allow achieving optimal DL indicators, is actual. The conventional approach based on PT, VSA and impedance measurements do not take into 
account myocardial perfusion abnormalities (particularly myocardial scar) in the most common segments for DL implantation (apical and septal). This can lead to PT increase, VSA decrease, impaired detection of the ventricular signal and frequent inappropriate ICD-therapy, which can reduce ICD battery consumption and affect the quality of patient life [13-17].

Our analysis showed that ICD implantation in patients for whom DL positioning was optimized in accordance with the myocardial perfusion scintigraphy, reduced PT by $29.0 \%(p=0.03)$ in the early and by $40.0 \%(p=0.01)$ in a long-term follow-up. In these patients, PT was minimal, respectively, the pacing amplitude was lower and the energy consumption was significantly lower than in patients for whom ICD was implanted using conventional approaches. Bring to light that DL implantation into the zone of the least ischemic disorder leds to VSA increase by $28.0 \%(p=0.03)$ in early and by $48.0 \%(p=0.01)$ in a long-term follow-up. The analysis revealed that patients with ICD implanted using conventional approaches had VSA decrease tendency.

Recently research indicates that the VSA should not be lower than $5.0 \mathrm{mV}$ and the optimal VSA should be not less than $7.0 \mathrm{mV}$ [5]. At the same time, according to our data, in $23(79.3 \%)$ patients from the $2 \mathrm{nd}$ group with ICD implanted using conventional approaches VSA was less than $7.0 \mathrm{mV}(p<0.001)$, which could increase the risk of "undersensing", as a result the device was not be able correctly and betimes detect life-threatening ventricular arrhythmias, and SCD risk remained high, even with an implanted cardioverter-defibrillator.

Because ICD adjusts sensitivity in relation to the amplitude of each sensed R-wave, the risk of both Twave oversensing and VT/VF undersensing is higher when R-waves (VSA) are small [18]. In the presence of constant, low-amplitude R-waves (VSA), repositioning the defibrillation lead or adding a separate sense/pace lead is required to ensure VT/VF detection and avoid T-wave oversensing if the sensing vector is not programmable [18]. Causes of intracardiac signals hyposensitivity are improper programming of device sensitivity parameters, fibrosis of lead tip contact with the endomyocardium, cardiac signal amplitude decrease, hyperkalemia, high doses of antiarrhythmic drugs, lead dislocation and damage. T-wave oversensing can inhibit stimulation and lead to bradycardia. If an ICD is implanted, sinus tachycardia can be interpreted as ventricular tachycardia and inappropriate ICD-therapy will be carried out in accordance with the ICD program (ATP, shock) [19]. It was found that PT maximum values and the ventricular signal minimum amplitude were detected on the 7th day after ICD implantation, which corresponded to the lead "maturation" term. Significant differences were also obtained in terms of impedance, but no excessively high or low values were recorded. When changing the lead impedance with a difference of $200 \mathrm{Ohms}$ in one direction or another compared to the previous value, especially in combination with PT and VSA disturbances, it would require a meticulously ICD-lead system assessment, but in our study there were no such lead impedance scatter. Fibrosed myocardial tissue, in contrast to intact myocardial tissue, may have low electrical conductivity and electrical activity. And the greater the degree of fibrosis at the contact of the lead tip with the endomyocardium, the more electrical energy will be required to stimulate the endomyocardium. This increases the pacing threshold and decrease intracardiac signal amplitude. 
We failed to find any publications concerning the similar studies. In our opinion, the closest in fact are scientific works in which the prognostic value of myocardium perfusion scintigraphy for the effectiveness of cardiac resynchronization therapy predicting in patients with the chronic heart failure and left ventricle dysfunction was studied [20]. The authors Sommer A. et al. in 2016, showed the effectiveness of using the results of multimodal imaging methods, including the myocardium perfusion scintigraphy, for the left ventricular lead placement in cardiac resynchronization therapy [20].

The limitations of the study include a relatively small sample of patients, follow-up duration and the fact that it is single-center study, which can reduce the value of results.

\section{Conclusion}

Results of the current study have shown that the presence of hypoperfusion or scarring detected by MPS in the area of the DL placement worsens its parameters. The results of MPS in patients with CAD can be useful for optimization of DL placement. The new approach for ICD placement, considering MPS results, allows achieving the optimal lead indicators (PT 1.0 V or less, VSA $5.0 \mathrm{mV}$ or more), thereby improving ventricular signal detection. DL implantation into the zone of the smallest perfusion disorder assessed by the myocardial perfusion scintigraphy reduces PT by $40.0 \%(p=0.01)$ and increases VSA by $48.0 \%(p=$ 0.01 ) in early and a long-term follow up.

\section{Abbreviations}

ICD - implantable cardioverter-defibrillator

SCD - sudden cardiac death

VT - ventricular tachycardia

VF - ventricular fibrillation

VSA - ventricular signal amplitude

DL - defibrillation lead

PT - pacing threshold

CAD - coronary artery disease

$\mathrm{Ml}$ - myocardial infarction

${ }^{99 m}$ Tc-MIBI - ${ }^{99 m}$ Tc-methoxy-isobutyl-isonitrile

SPECT - single-photon emission computed tomography 
SRS - summed rest score

$\mathrm{AF}-$ atrial fibrillation

$\mathrm{PI}$ - pace impedance

SI - shock impedance

\section{Declarations}

\section{Conflict of interests:}

none declared. No funds, grants, or other support was received.

\section{References}

1. Epstein AE, DiMarco JP, Ellenbogen KA et al (2013) 2012 ACCF/AHA/HRS Focused update incorporated into the ACCF/AHA/HRS 2008 guidelines for device-based therapy of cardiac rhythm abnormalities. J Am Coll Cardiol. https://doi.org/10.1016/j.jacc.2012.11.007

2. Bruggeman T, Dahlke D, Chebbo A, Neumann I (2016) Tachycardia detection in modern implantable cardioverter-defibrillators. Herzschrittmacherther Elektrophysiol. https://doi.org/10.1007/s00399016-0499-z

3. Zeitler EP, Sanders GD, Singh K et al (2018) Single vs. dual chamber implantable cardioverterdefibrillators or programming of implantable cardioverter-defibrillators in patients without a bradycardia pacing indication: systematic review and meta-analysis. Europace. https://doi.org/10.1093/europace/euy183

4. Friedman PA, Bradley D, Koestler C et al (2014) A prospective randomized trial of single- or dual chamber implantable cardioverter-defibrillators to minimize inappropriate shock risk in primary sudden cardiac death prevention. Europace. https://doi.org/10.1093/europace/euu022

5. Swerdlow CD, Russo AM, Degroot PJ (2007) The dilemma of ICD implant testing. Pacing Clin Electrophysiol 30(5):675-700

6. Wilkoff BL, Fauchier L, Stiles MK et al (2016) 2015 HRS/EHRA/APHRS/SOLAECE expert consensus statement on optimal implantable cardioverter-defibrillator programming and testing. Europace. https://doi.org/10.1093/europace/euv411

7. Zecchin M, Solimene F, D'Onofrio A et al (2020) Atrial signal amplitude predicts atrial high-rate episodes in implantable cardioverter defibrillator patients: Insights from a large database of remote monitoring transmissions. J Arrhythm. https://doi.org/10.1002/joa3.12319

8. Amoros-Figueras G, Jorge E, Alonso-Martin C et al (2018) Endocardial infarct scar recognition by myocardial electrical impedance is not influenced by changes in cardiac activation sequence. Heart Rhythm. https://doi.org/10.1016/j.hrthm.2017.11.031 
9. Burkland DA, Ganapathy AV, John M et al (2017) Near-field impedance accurately distinguishes among pericardial, intracavitary, and anterior mediastinal position. J Cardiovasc Electrophysiol. https://doi.org/10.1111/jce.13325

10. Powell BD, Asirvatham SJ, Perschbacher DL et al (2012) Noise, artifact and oversensing related inappropriate ICD shock evaluation: ALTITUDE noise study. Pacing Clin Electrophysiol. https://doi.org/10.1111/j.1540-8159.2012.03407.x

11. Pang BJ, Joshi SB, Lui EH et al (2014) Validation of conventional fluoroscopic and ECG criteria for right ventricular pacemaker lead position using cardiac computed tomography. Pacing Clin Electrophysiol. https://doi.org/1111/pace.12301

12. Hesse B, Tagil K, Cuocolo A et al (2005) EANM/ESC procedural guidelines for myocardial perfusion imaging in nuclear cardiology. Eur J Nucl Med Mol Imaging 32(7):855-897

13. Amit G, Wang J, Connolly SJ et al (2016) Apical versus non-apical lead: is ICD lead position important for successful defibrillation? J Cardiovasc Electrophysiol. https://doi.org/1111/jce.12952

14. Bongiorni MG, Burri H, Deharo JC et al (2018) 2018 EHRA expert consensus statement on lead extraction: recommendations on definitions, endpoints, research trial design, and data collection requirements for clinical scientific studies and registries: endorsed by APHRS/HRS/LAHRS. Europace. https://doi.org/10.1093/europace/euy050

15. Boriani G, Merino J, Wright DJ et al (2018) Battery longevity of implantable cardioverter-defibrillators and cardiac resynchronization therapy defibrillators: technical, clinical and economic aspects. An expert review paper from EHRA. Europace. https://doi.org/10.1093/europace/euy066

16. von Gunten S, Schaer BA, Yap SC et al (2016) Longevity of implantable cardioverter defibrillators: a comparison among manufacturers and over time. Europace. https://doi.org/10.1093/europace/euv296

17. Manolis AS, Maounis T, Koulouris S, Vassilikos V (2017) "Real life" longevity of implantable cardioverter-defibrillator devices. Clin Cardiol. https://doi.org/10.1002/clc.22729

18. Cao J, Gillberg JM, Swerdlow CD (2012) A fully automatic, implantable cardioverter-defibrillator algorithm to prevent inappropriate detection of ventricular tachycardia or fibrillation due to T-wave oversensing in spontaneous rhythm. Heart Rhythm. https://doi.org/10.1016/j.hrthm.2011.11.023

19. Wilson DG, Leventigiannis G, Barr C, Morgan JM (2016) ECG predictors of T wave oversensing in subcutaneous implantable cardioverter defibrillators. Int J Cardiol. https://doi.org/10.1016/j.ijcard.2016.06.128

20. Sommer A, Kronborg MB, Norgaard BL et al (2016) Multimodality imaging-guided left ventricular lead placement in cardiac resynchronization therapy: a randomized controlled trial. Eur J Heart Fail. https://doi.org/1002/ejhf.530

\section{Figures}




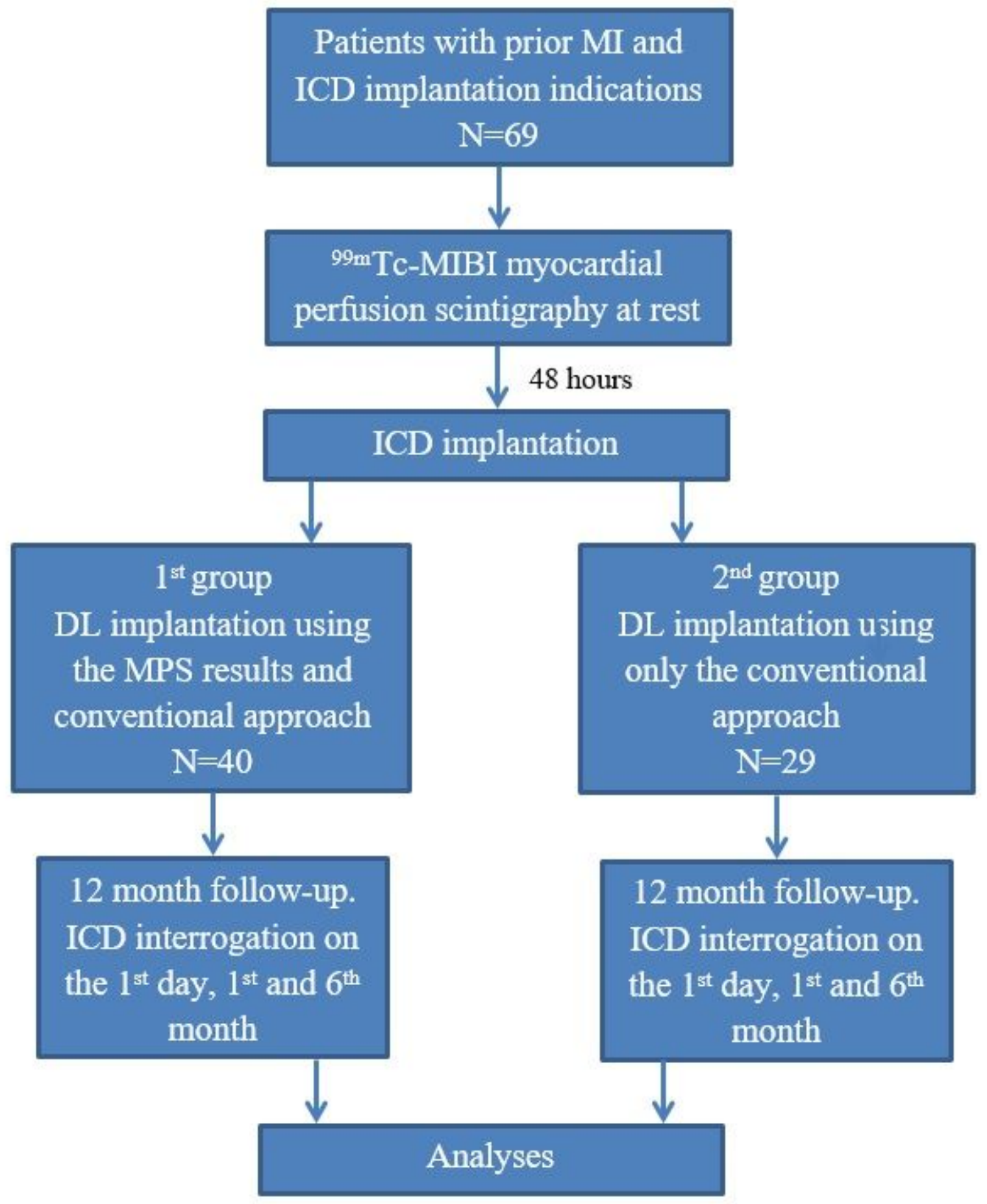

Figure 1

Flow chart of the study 


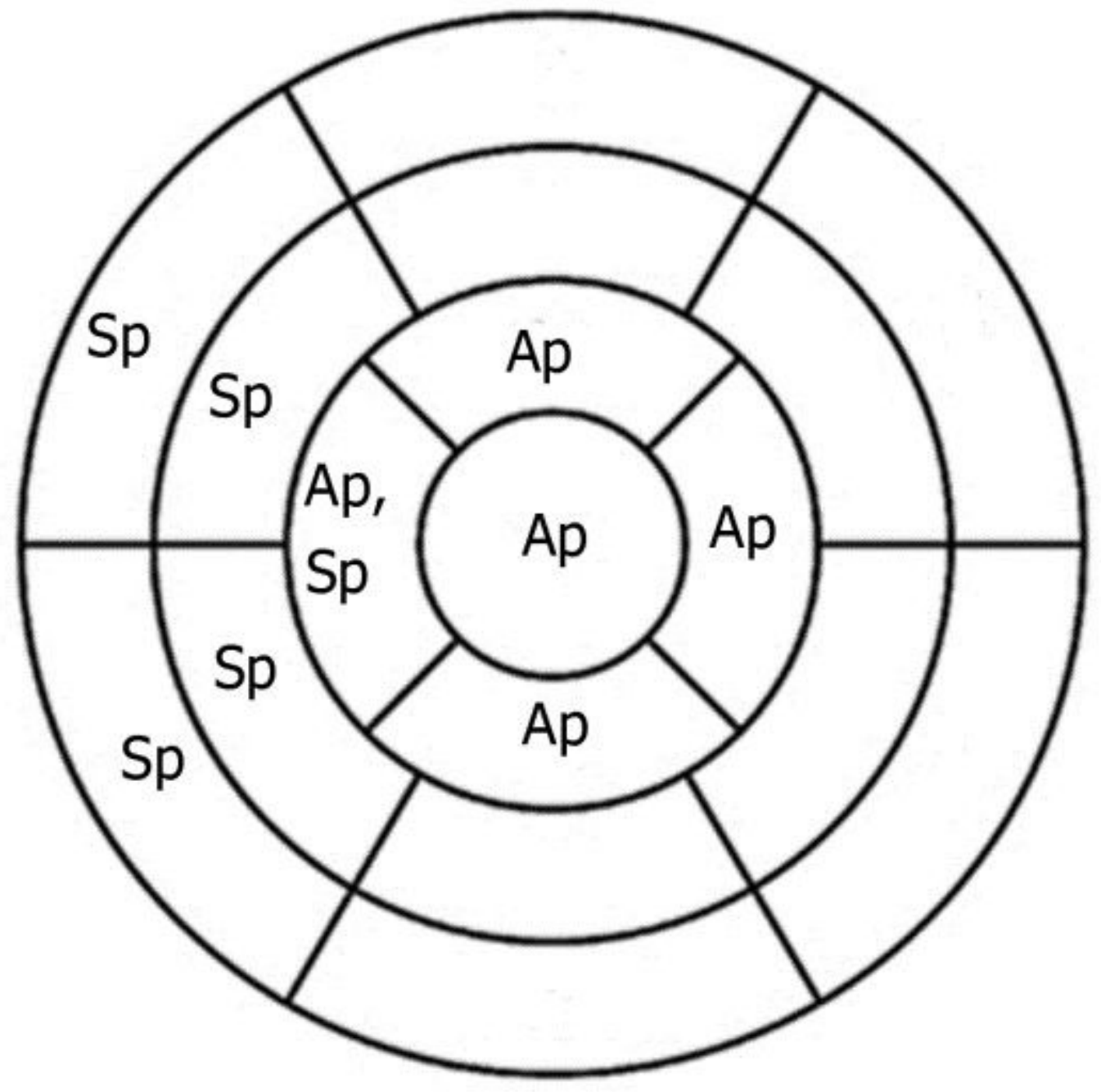

Figure 2

Segmental polar map of left ventricle. Ap - apical segments, Sp - septal segments 

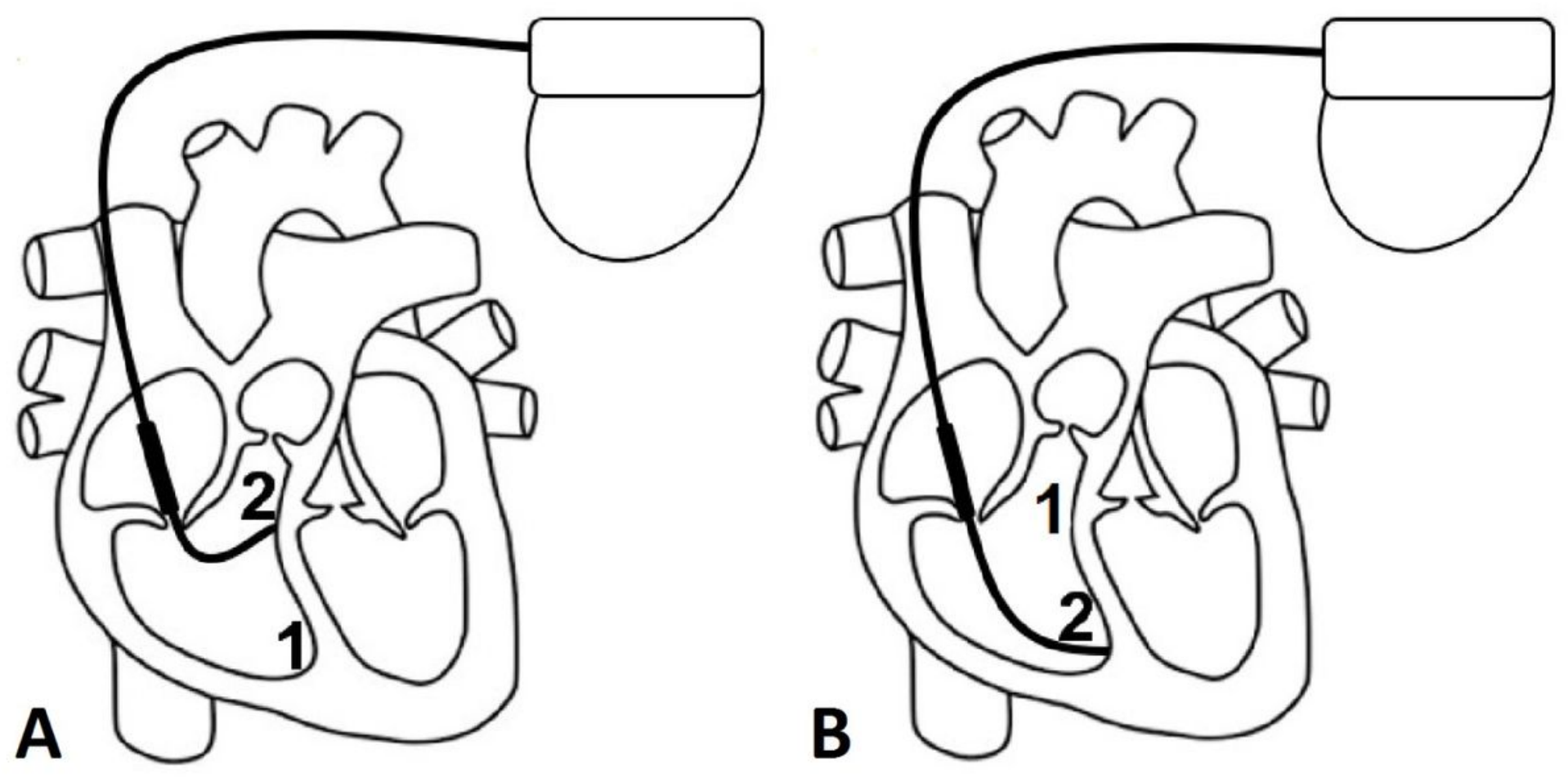

Figure 3

The scheme of defibrillation lead implantation technique in the 1st group. A - defibrillation lead implanted to the septal position (1 - myocardial perfusion defect in the apex, 2 - lead was implanted in septum); B - defibrillation lead implanted to the apical position (1 - myocardial perfusion disorders in the septum, 2 - lead was implanted in apex) 


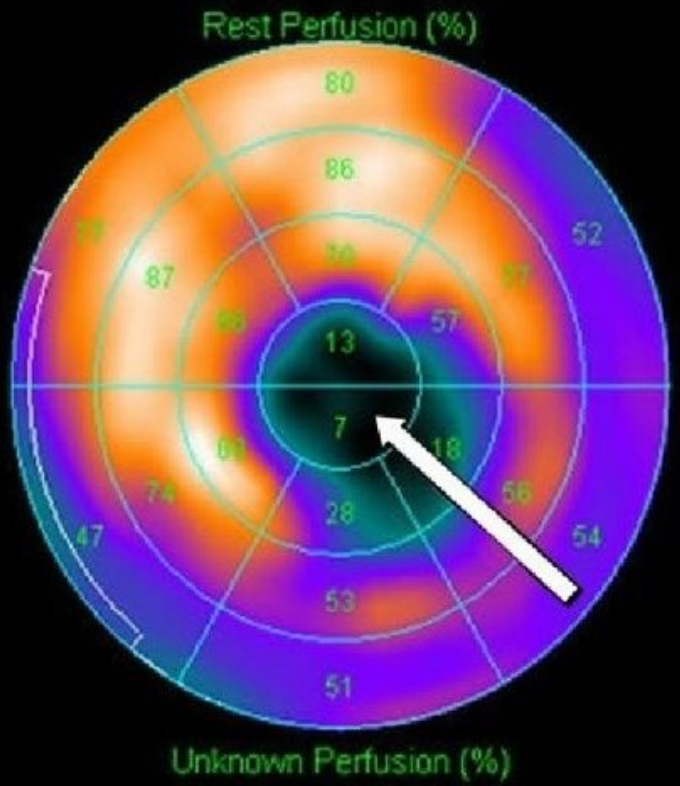

Rest Perfusion (\%)

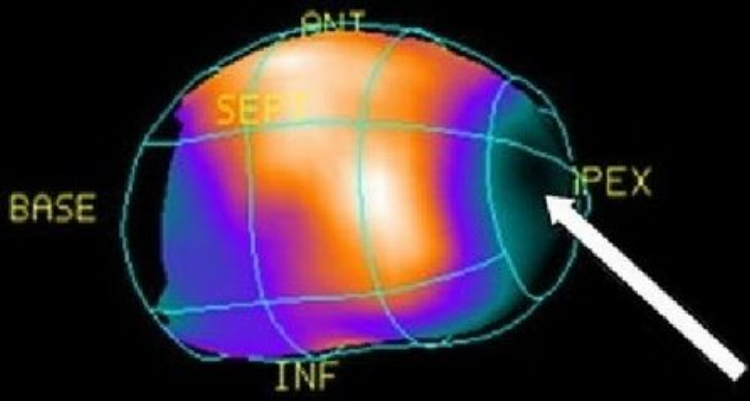

Unknown Perfusion (\%)

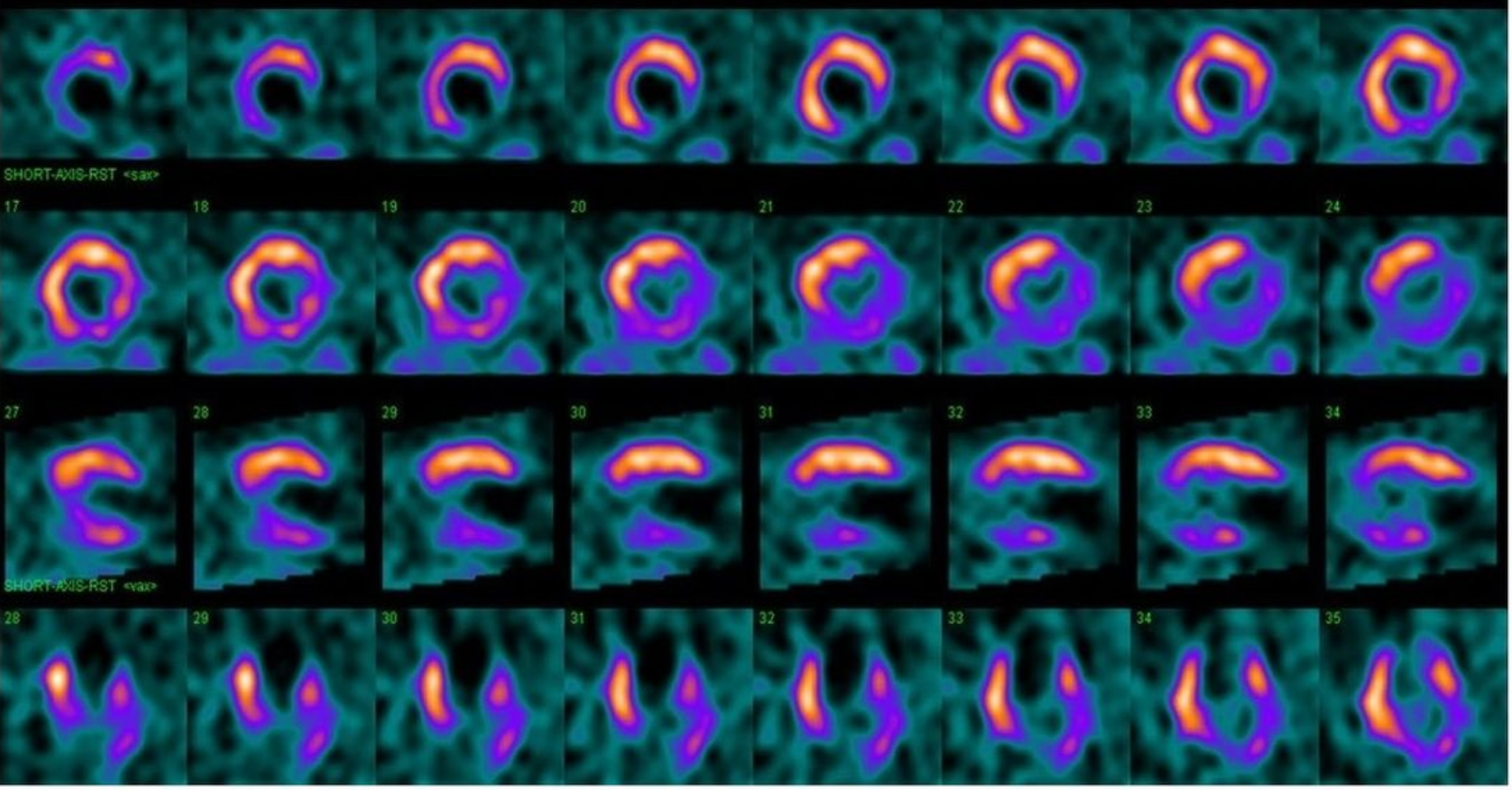

\section{Figure 4}

Myocardial perfusion scintigraphy with $99 \mathrm{mTC}-\mathrm{MIBI}$ of patient from the 1 st group, male, 58 year old, with ICD implantation indication for the secondary SCD prevention. Left ventricle ejection fraction was 65\%, summed rest score - 38\%, summed apex score was 8 (indicated by an arrow) and summed septum score was 2. Defibrillation lead was implanted to the zone of the smallest perfusion disorders (myocardial scar), that is septum. During 12th month follow-up optimal defibrillation lead indicators were observed 

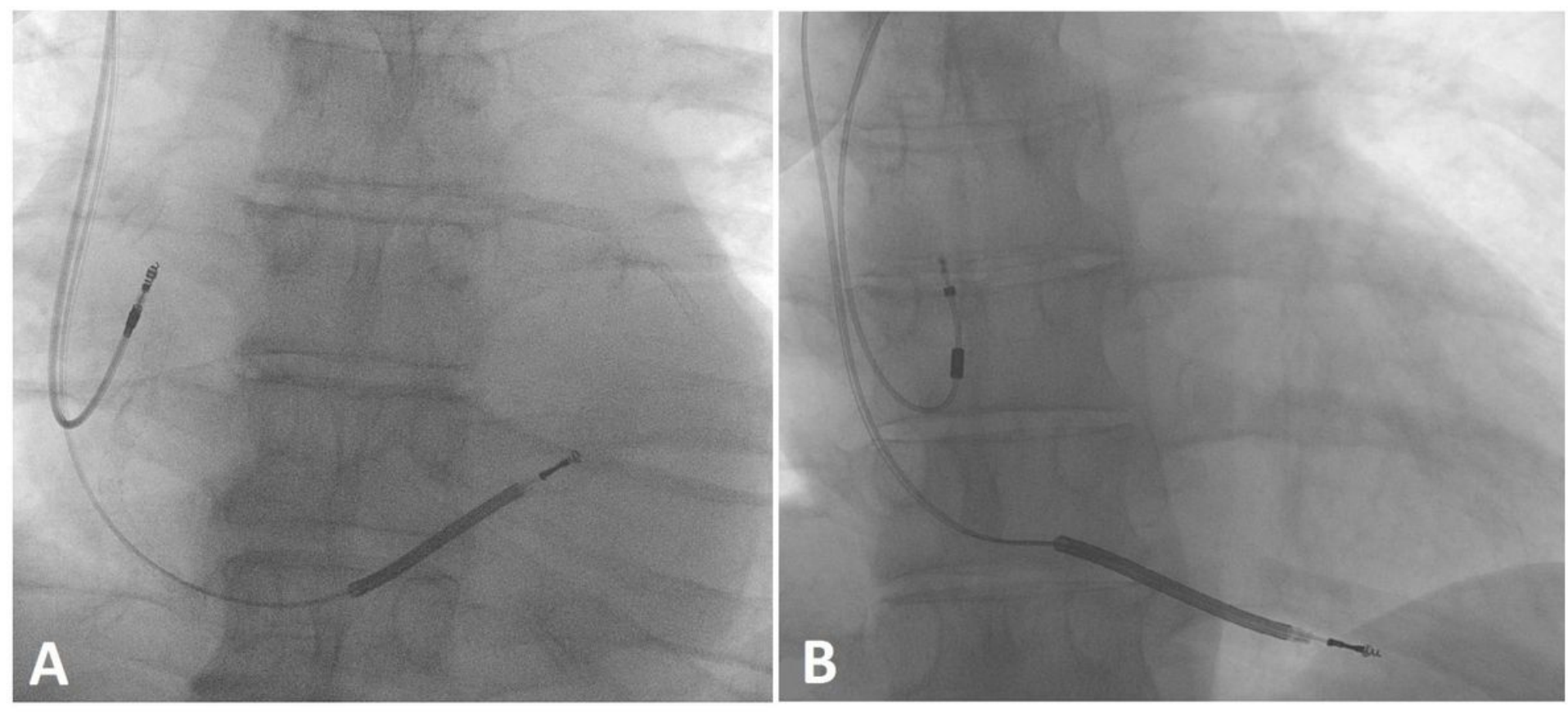

\section{Figure 5}

X-ray pictures in anteroposterior view. A - defibrillation lead implanted to the septal position; B defibrillation lead implanted to the apical position

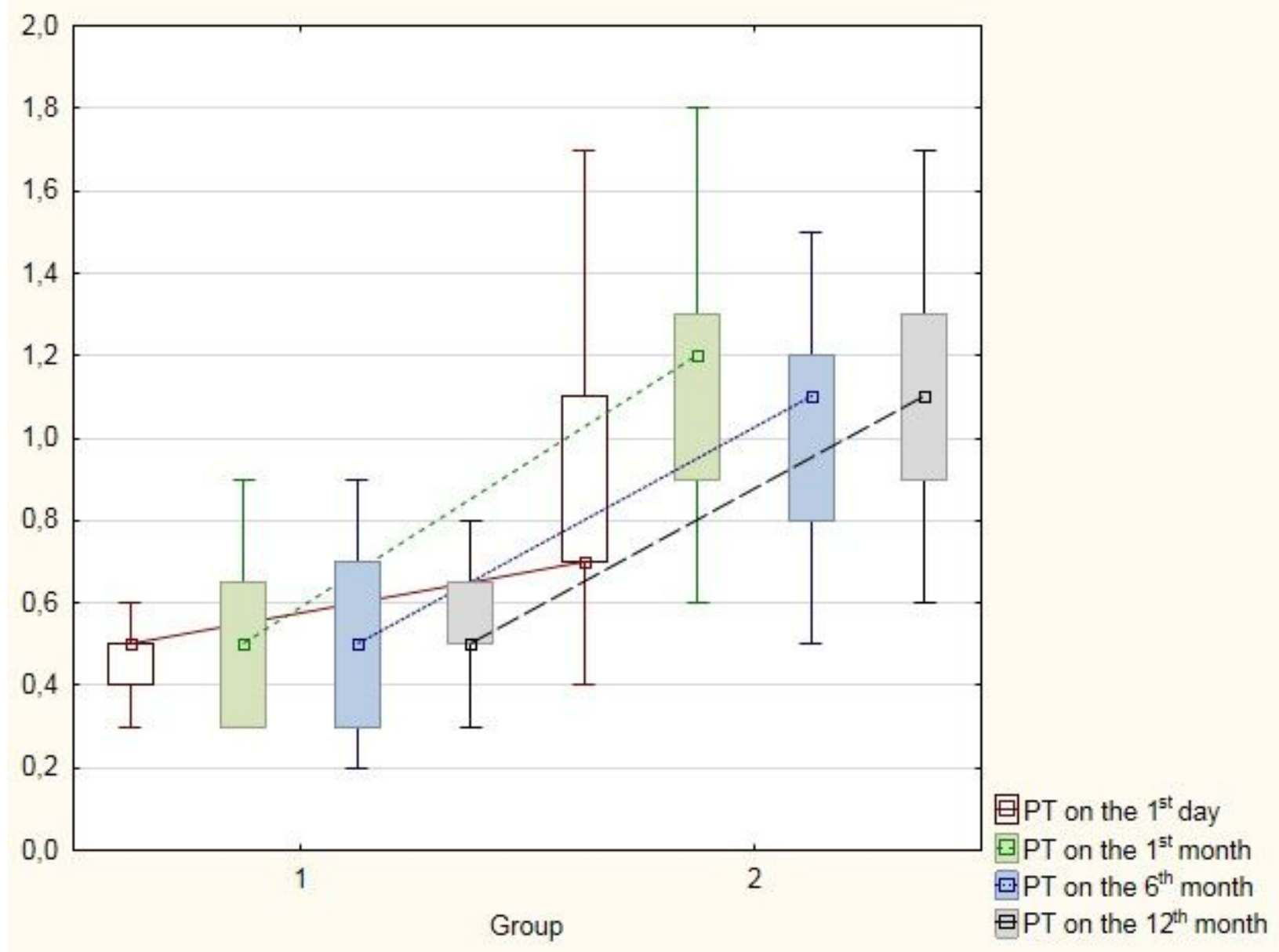

Figure 6 
The PT dynamics in groups at all follow-up points. PT - pacing threshold

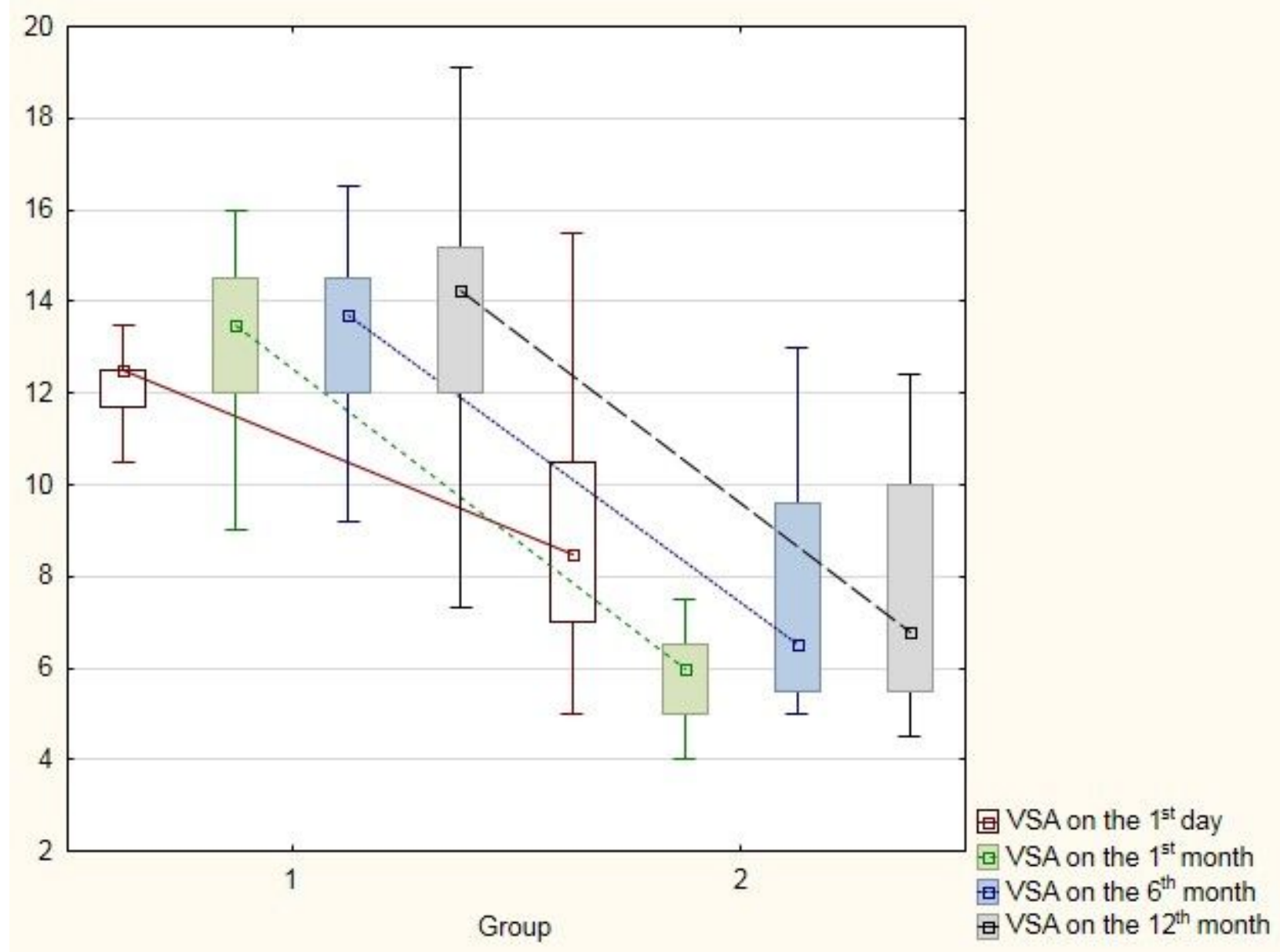

Figure 7

The VSA dynamics in groups at all follow-up points. VSA - ventricular signal amplitude 